\title{
PERCEPÇÃO DO PROFESSOR SOBRE O PROCESSO DE ALFABETIZAÇÃO
}

\author{
TEACHER PERCEPTION OF LITERACY PROCESS
}

\author{
LUISAHELENABRAMBILLA \\ ANAANGÉLICAJÚLIO \\ Psicóloga e Pedagoga, respectivamente \\ e Mestres em Psicologia Escolar
}

\begin{abstract}
RESUMO
Este estudo procurou identificar fatores que interferem no processo de alfabetização, e como foco de atenção principal, a visão do professor sobre esse processo. A amostra constitui-se de 20 professores da primeira série do ciclo básico de três escolas estaduais, situadas em duas cidades do interior do Estado de São Paulo. Os professores responderam a um questionário contendo quatro questões abertas. A análise dos resultados aponta a alfabetização para o professor, fundamentalmente como uma forma de aprender a escrever. Num percentual menor, adquirir conhecimentos e ler. As dificuldades para alfabetizar não estão bem definidas para o professor, mas há uma tendência que aponta para a instituição escolar, com suas salas numerosas e no conhecimento prévio trazido pelo aluno está o elemento facilitador do processo.
\end{abstract}

Palavras-chave: Alfabetização, Percepção do Professor, Psicologia Escolar

\section{SUMMARY}

This study was search to identify factors which interfere with the literacy process, and was mainly focused on the teacher's view of this process. The sample consisted of twenty first year's elementary school teachers from three public schools in two country cites of São Paulo State. The teachers answered a questionnaire of four open questions. The analysis of the results showed that, for the teachers, the literacy is basically, a way of learning to write. In smaller percentage, acquiring knowledge and read. The difficulties in the literacy process aren't clear to the teachers, but there is a tendency in appoint to the school institutions, whith our full classes, but the student previous knowledge eases the literacy process.

Keywords: Literacy, Teacher's Perception, School Psychology 


\section{INTRODUÇÃO}

A busca na identificação de aspectos que contribuem para o sucesso ou fracasso escolar durante o processo de alfabetização, conduziu as Autoras a pesquisas referentes aos fatores intervenientes na relação professor-aluno em sala de aula.

A hipótese levantada na presente pesquisa baseia-se na crença de que professor e aluno trazem para o ambiente escolar, sua história, suas idéias, concepções e expectativas mútuas do que deverá ocorrer em sala de aula durante o processo de alfabetização. Esses elementos subjetivos devem possuir uma influência nessa interação e necessitam ser conhecidos para que se possa delinear melhor as proporções de seu campo de atuação no grau de dificuldades e facilidades encontradas pelos alunos durante o processo de alfabetização. Dessa ampla questão, este trabalho restringe-se a tentar investigar o que pensa $o$ professor alfabetizador, em termos genéricos, sobre a alfabetização.

Segundo COOK-GUMPERZ(1991, p.19), a primeira tarefa das pesquisas é explorar em detalhes a prática da alfabetização sem fazer julgamentos, mas sim descobrindo os preconceitos que afetam esta prática e analisando "os modos pelos quais uma ideologia da alfabetização entra em nossas avaliações da eficiência educativa".

Apesar de amplamente debatida, alfabetização é uma palavra de difícil conceituação, possuindo distintas definições que dependem do enfoque de diversos estudiosos no assunto.

A palavra "literacy" (alfabetização) vem do latim-literatus, que significa pessoa culta, conforme VENEZKY (1990).

Segundo MACIAS (1990), ler significa dar sentido (ou significado) ao texto impresso e escrever e usar a escrita como o sistema de signos que contém significados.

Para MIKULECKY (1990), as definições de alfabetização estão em constante ampliação e muitas concepções errôneas do termo têm comprometido decisões educacionais e políticas, que se relacionam a alfabetização. Essas decisões servem a propósitos e são influenciadas pelas tendências sociais, comerciais e políticas dominantes.

FERREIRO (1988) afirma não haver neutralidade em nenhuma prática pedagógica, estando todas elas apoiadas em certo modo de conceber o processo e o objeto da aprendizagem.

FREIRE \& MACEDO (1990) condenam a redução da visão de alfabetização como um mero trabalho com letras e palavras de modo mecânico, preferindo encará-la como uma relação entre os educandos e o mundo, mediada pela prática transformadora desse mundo.

Assim também, COLELLO (1995) acredita que a alfabetização deve, desde o início, estar articulada com os esforços de integrar o indivíduo no contexto do seu mundo, na compreensão dos outros, promovendo novas maneiras de organização do pensamento e possibilitando ao indivíduo a ação na construção do conhecimento, a manifestação de si mesmo.

Discutindo o tema, COOK-GUMPERZ (1991) afirma que a alfabetização se refere à capacidade de compreensão e de criação das mensagens impressas, assim como às mudanças decorrentes desta capacidade. A autora citada vê a alfabetização como um fenômeno socialmente construído e ressalta que a maneira como vemos as conseqüências da alfabetização, está em sua essência, relacionada com nossa definição ou avaliação da atividade de alfabetização.

A criança, mesmo as advindas de meioambiente menos letrado, não entram na escola sem qualquer influência da língua escrita. Segundo MORO (1992), várias instituições socioculturais, antes da escola, fizeram e estarão fazendo a transmissão cultural à criança, através da interação social.

Ainda segundo a autora supra citada, esse fato deve fazer o professor levar em conta e 
tentar identificar o "nível de elaboração prévia sobre escrita de seus alunos, ao ser iniciado o processo mais sistemático de alfabetização" (p.37). Dessa forma pode-se explorar os atributos do aluno embenefício próprio, desenvolvendo estratégias para chegar ao objetivo da alfabetização, prevenindo o fracasso escolar.

Conscientes da importância do professsor no processo de ensino-aprendizagem, algumas das pesquisas brasileiras baseadas em conceitos atribucionais, têm nele seu foco de atenção principal, (MALUF \& BARDELLLI,1991; GAMA \& JESUS, 1994; NEVES \& ALMEIDA, 1996).

Segundo as hipóteses de Bernard Weiner (1972,1980), citado por MALUF E BARDELLI (1991, p.264),"a percepção da causa do sucesso ou fracasso escolar pelo professor e pelo aluno é um fator determinante ou codeterminante do comportamento de cada um. A atribuição de causalidade, enquanto configuração cognitiva, atua como um elemento mediador das relações interpessoais, com conseqüências no desempenho escolar do aluno".

No trabalho de GAMA \& JESUS (1994),os dados indicaram que os professores do $1^{\circ}$ grau deslocam a questão do fracasso escolar para uma responsabilidade individual do aluno e de sua família (interesse, esforço e situação econômica). Em todas as séries da amostra, os alunos que foram reprovados eram considerados menos inteligentes, dos quais se esperava desempenho final inferior e tempo menor de escolaridade.

Em pesquisa menos atual, MARIZ (1985) já afirmava que a criança carente é vista como vítima da situação econômica precária da família pelas suas professoras. Não foi apresentada pelos professores dessa pesquisa nenhuma autocrítica, constatando-se preconceito e desvalorização do estilo das famílias dos alunos.

NEVES \& ALMEIDA (1996) pesquisaram o fracasso escolar em estudantes repetentes da 5a série, abrangendo a perspectiva dos alunos, dos professores e de seus pais. Neste estudo, os alunos apontaram a si mesmos como responsáveis pelo fracasso, as causas internas (esforço, motivação), enquanto os professores atribuíram à falta de preparo do aluno e deficiência na ajuda dos pais. No entanto, a ajuda dos pais não foi citada pelos alunos e teve freqüência muito baixa por parte dos pais. Os pais atribuíram à falta de motivação e preparo dos filhos a responsabilidade do fracasso.

BRANDÃO, BAETA \& ROCHA ( 1983), observaram na atitude do professor, um conjunto de estereótipos e preconceitos em relação aos alunos, sobretudo os mais "carentes". Além disso, foi notada uma preocupação em patologizar os alunos. Suas famílias eram também encaradas deforma depreciativa.

ROSENTHAL (1973), comentando o impacto de seu livro com Jacobson em 1968, sobre o efeito pigmaleão em sala de aula -a chamada profecia auto-realizável - onde o professor prevê o fracasso ou sucesso dos alunos com antecedência e este acaba por ser confirmado - demonstrou de forma inquestionável a importância decisiva de variáveis como as expectativas, padrões de atribuição causal, percepções e representações pessoais da capacidade para o desempenho.

Conscientes da importância do papel do professor dentro do processo de ensino-aprendizagem de leitura e escrita, no presente estudo, centramo-nos na identificação da visão do professor da primeira série do primeiro grau, sobre o processo de alfabetização.

\section{Método}

\section{Sujeitos}

Foram sujeitos da amostra 20 professores de escolas estaduais da primeira série do ciclo básico, que concordaram participar da pesquisa, todos eram do sexo feminino. A faixa etária de maior concentração possuía idade entre 36 e 45 anos (50\%), que variou de 22 a 50 anos. Quanto ao nível de instrução, 70\% das professoras possuía nível superior. O tempo 
mínimo de experiência como professora alfabetizadora encontrado foi de um ano, sendo que $45 \%$ oscilaram entre 1 e 5 anos de experiência e outros $45 \%$ entre 10 e 15 anos nesta atividade específica.

\section{Material}

O instrumento elaborado para a investigação constou de um questionário composto por quatro questões abertas buscando obter informações sobre a visão do professor sobre a alfabetização. As questões foram : "O que é alfabetização para você?"; "O que dificulta o processo de alfabetização, na sua opinião?"; "Na sua opinião, o que contribui para que a alfabetização da criança aconteça?"; "Em sua opinião, acriançada 1 a série compreende o que faz na escola? Explique".

\section{Procedimento}

Os questionários foram entregues aos professores nas respectivas escolas para o pos- terior preenchimento, sendo recolhidos pelos pesquisadores no período máximo de dois dias. Solicitou-se aos mesmos que respondessem às questões de acordo com sua vivência enquanto professores alfabetizadores.

\section{RESULTADOS}

As respostas dos questionários foram avaliados por meio do método de análise de conteúdo (KELINGER, 1975; BARDIN, 1979; DIAZ, 1992).

Os resultados da Tabela 1 demonstram existir uma diferença significante no pensamento dos vários professores sobre o conceito de alfabetização, $\left(X_{0^{2}}=39,67\right)$. Houve uma tendência das respostas dos professores a cerca do conceito de alfabetização, que parece ancorado no aprendizado da escrita $\left(\mathrm{Xo}^{2}=47,51\right)$. Apesar de não demonstrarem significância, houve uma alta porcentagem de respostas incluindo a aquisição de conhecimento,(14,28\%) e a aprendizagem da leitura (13,18\%), no conceito de alfabetização pelos sujeitos da amostra.

TABELA 1 QUESTĀO "A":

Concepções de alfabetização entre os docentes pesquisados

\begin{tabular}{|c|c|c|c|c|c|c|}
\hline $\begin{array}{l}\text { Categorias } \\
\text { globais }\end{array}$ & $\mathrm{F}$ & $\%$ & $\mathrm{Xo}^{2}$ & $\begin{array}{l}\text { categorias } \\
\text { iniciais }\end{array}$ & $\mathrm{F}$ & $\%$ \\
\hline \multirow[t]{4}{*}{$\begin{array}{l}\text { Aprendizagem de } \\
\text { leitura e escrita }\end{array}$} & 42 & 46.15 & 47.51 & Escrita & 16 & 17.58 \\
\hline & & & & Leitura & 12 & 13.18 \\
\hline & & & & Conhecimento & 13 & 14.28 \\
\hline & & & & Aprendizagem & 1 & 1.09 \\
\hline \multirow[t]{3}{*}{ Inovaçāo } & 12 & 13.19 & 0.41 & Criatividade & 6 & 6.59 \\
\hline & & & & Criticidade & 5 & 5.49 \\
\hline & & & & Desafiar & 1 & 1.09 \\
\hline \multirow[t]{5}{*}{ Evolução social } & 14 & 15.38 & 0.15 & Integração & 4 & 4.39 \\
\hline & & & & Socializaçăo & 2 & 2.19 \\
\hline & & & & Comunicaçāo & 5 & 5.49 \\
\hline & & & & Progressos & 3 & 3.29 \\
\hline & & & & Continuidade & 6 & 6.59 \\
\hline Tempo & 7 & 7.69 & 1.07 & Respeito ao ritmo & 1 & 1.09 \\
\hline \multirow[t]{3}{*}{ Evolução pessoal } & 6 & 6.60 & 5.53 & Pensar & 1 & 1.09 \\
\hline & & & & Compreensão & 4 & 4.39 \\
\hline & & & & Auto-organização & 1 & 1.09 \\
\hline \multirow[t]{2}{*}{ Cotidiano } & 10 & 10.99 & 0.68 & Ambiente escolar & 7 & 7.69 \\
\hline & & & & Cotidiano & 3 & 3.29 \\
\hline TOTAL & 91 & $100 \%$ & 39.67 & TOTAL & 91 & $100 \%$ \\
\hline
\end{tabular}


Os dados da Tabela 2 demonstram que os professores da amostra parecem não ter conseguido identificar com clareza as maiores dificuldades por eles encontrados no processo de alfabetização $\left(\mathrm{Xo}^{2}=0,8\right)$. Apesar do amplo número de respostas por eles apresentadas, pode-se observar que, percentualmente, parece haver uma tendência dos sujeitos a destacar as dificuldades presentes na instituição escolar $(31,58 \%)$, com suas salas numerosas.

\section{TABELA 2 QUESTÃO "B":}

Dificuldades no processo de alfabetização identificadas pelos docentes

\begin{tabular}{|c|c|c|c|c|c|c|}
\hline Câtégorias̄s glọbais & $F$ & $\%$ & $X_{0}{ }^{2}$ & $\begin{array}{c}\text { Categorias } \\
\text { inicias }\end{array}$ & $\mathrm{F}$ & $\%$ \\
\hline \multirow[t]{5}{*}{ Instituiçăo Escolar } & 24 & 31.58 & 0.31 & Salas numerosas & 10 & 13.15 \\
\hline & & & & Material didático & 8 & 10.52 \\
\hline & & & & $\begin{array}{l}\text { Atençăo dos } \\
\text { governantes }\end{array}$ & 3 & 3.94 \\
\hline & & & & Ambiente alfabetizador & 1 & 1.31 \\
\hline & & & & Falta de especialistas & 2 & 2.63 \\
\hline \multirow[t]{2}{*}{ Pais } & 16 & 21.05 & 0.31 & Pais & 13 & 17.10 \\
\hline & & & & Problemas Sociais & 3 & 3.94 \\
\hline \multirow[t]{3}{*}{ Protessor } & 18 & 23.68 & 0.10 & Tempo do professor & 3 & 3.94 \\
\hline & & & & Visăo do Professor & 9 & 11.84 \\
\hline & & & & Reciclagem & 6 & 7.90 \\
\hline \multirow[t]{5}{*}{ Aluno } & 18 & 23.68 & 0.10 & Desinteresse & 6 & 7.90 \\
\hline & & & & Necessidades básicas & 5 & 6.60 \\
\hline & & & & Dificuldade emocional & 1 & 1.31 \\
\hline & & & & Imaturidade & 5 & 6.60 \\
\hline & & & & Indisciplina & 1 & 1.31 \\
\hline TOTAL & 76 & $100 \%$ & 0.8 & Total & 76 & $100 \%$ \\
\hline
\end{tabular}

$$
X_{0^{2}}=0,8 ; X c^{2}=7,82 ; \text { n.sig. }=0.05 ; \text { n.g.l. }=3
$$

Os resultados da tabela 3 demonstram que os sujeitos da amostra parecem identificar na criança os fatores que contribuem para a efetivação do processo de alfabetização $\left(X 0^{2}=17,56\right)$. Na visão dos professores, o aluno contribuiria trazendo para a escola, o conhecimento prévio (12,90\%) e motivação (10,76\%).

A Tabela 4 apresenta em seus resultados, que a maioria dos professores acredita que a criança compreende o que vai fazer na escola 55\% e justificam esta posição argumentando que, podem observar esta compreensão através da aprendizagem que a criança demonstra na escola $\left(X^{2}=13,18\right)$, na habilidade de integração entre a fala e a escrita apresentada em sala de aula (11,30\%). No entanto, é importante ressaltar que uma parcela considerável desses professores, $30 \%$ acreditam que "nem sempre" a criança sabe o que faz na escola. 
TABELA 3 QUESTÃO "C":

Fatores que contribuem para a efetivação do processo de alfabetização da criança, segundo os docentes.

\begin{tabular}{|c|c|c|c|c|c|c|}
\hline Categorias globais & $F$ & $\%$ & $X_{0}^{2}$ & $\begin{array}{c}\text { Categorias } \\
\text { inicias }\end{array}$ & F \\
\hline Criança/Aluno & 32 & 34.40 & 17.56 & Motivação da criança & 10 & 10.76 \\
\hline & & & & Conhecimentos do aluno & 12 & 12.90 \\
\hline & & & & Prontidão & 7 & 7.52 \\
\hline & & & & Estímulo & 1 & 1.08 \\
\hline & & & & Negurança & 1 & 1.08 \\
\hline Ambiente escolar & 21 & 22.58 & 1.95 & Recursos escolares & 10 & 10.76 \\
\hline & & & & Ambiente escolar & 11 & 11.82 \\
\hline Professor & 19 & 20.43 & 0.79 & Formação do professor & 11 & 11.82 \\
\hline & & & & Trabalho em grupo & 1 & 1.08 \\
\hline & & & & Experiências concretas & 7 & 7.52 \\
\hline Pais & 10 & 10.75 & 0.70 & Atuação dos pais & 10 & 10.76 \\
\hline Interesse & 9 & 9.67 & 0.83 & Interesse & 9 & 9.67 \\
\hline Ajuda externa & 2 & 2.15 & 1.74 & Ajuda externa & 2 & 2.15 \\
\hline TOTAL & 93 & $100 \%$ & 17.03 & Total & 93 & $100 \%$ \\
\hline
\end{tabular}

TABELA 4 QUESTÃO "D":

Opinião dos docentes sobre a compreensão da criança sobre a função das atividades escolares

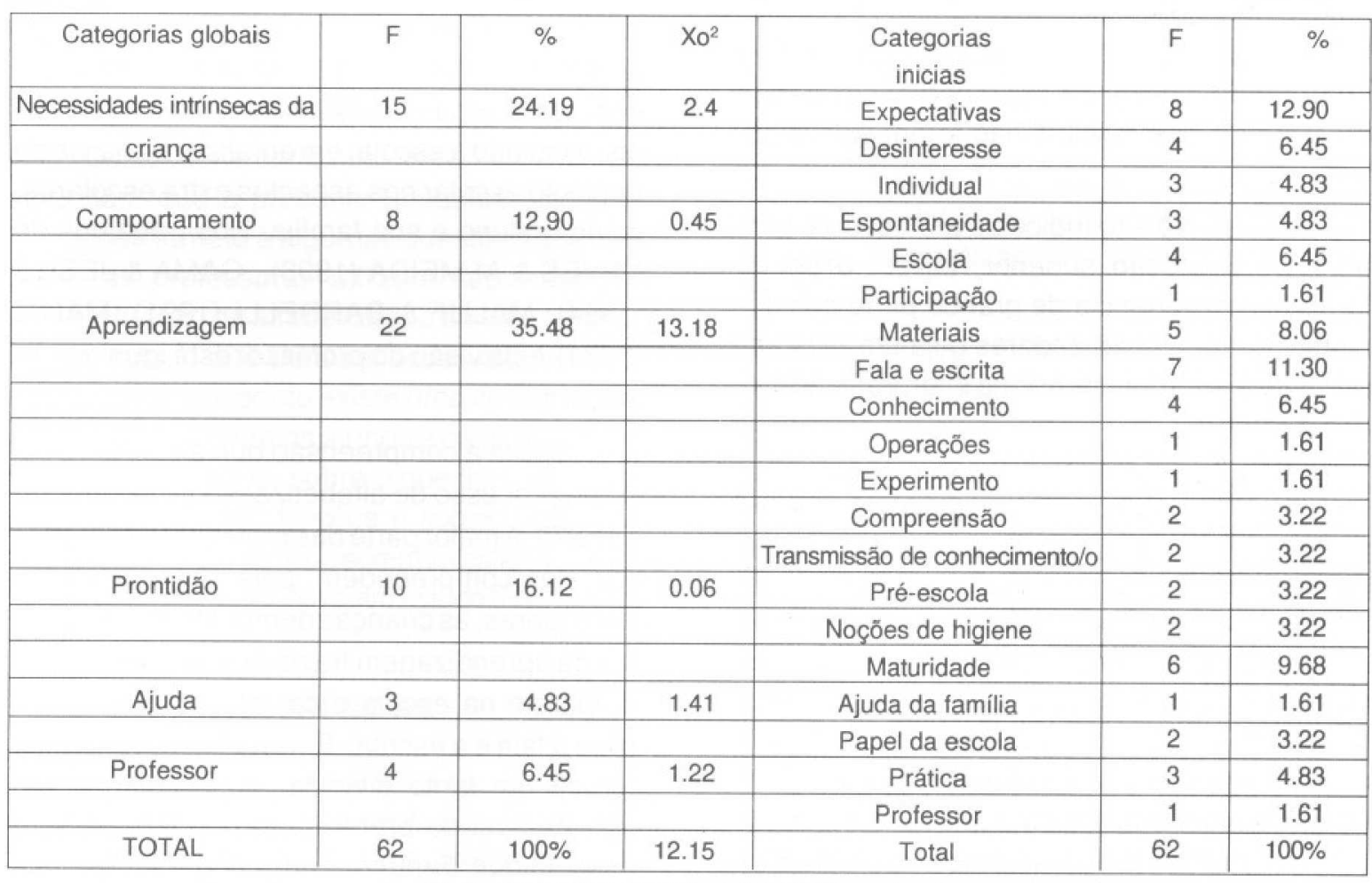

$X \mathrm{X}^{2}=12,15 ; X_{c^{2}}=11,07 ;$ n.sig. $=0.05 ;$ n.g.l. $=5$ 


\section{DISCUSSÃO}

Os resultados apresentados demonstraram que a alfabetização para estes professores é basicamente aquisição da escrita pela criança. Este conceito parece estar ligado a uma visão mais técnica da alfabetização, precedente aos anos 70, descrita por LEITE (1993). A obtenção de conhecimento e a aprendizagem da leitura, prosseguem no mesmo sentido, de uma função mais restrita na aplicação do conceito. Numa aplicação mais atualizada, ainda segundo o autor supra citado, passou nos anos 80 , a ser entendida com um caráter funcional do processo, ou seja, como condição de inserção do indivíduo no mundo.

Parece assim, consistir no aprendizado da escrita as suas expectativas para com a criança e tendo, provavelmente, os objetivos estabelecidos pelo professor em suas aulas fundamentados nessas metas. Respostas que incluíam uma visão mais ampla de alfabetização, incluindo a preocupação com sua utilidade, finalidade e aplicabilidade no mundo, como fator contribuinte na integração, criticidade e criatividade, apesar de aparecerem nos dados de resposta dos sujeitos não foram significativas.

Apesar do alto índice de professores com nível de instrução superior, talvez, o pouco tempo de experiência de grande parte dos docentes como alfabetizadores seja um fator importante a ser considerado na interpretação dos resultados.

Não houve um fator que se destacasse dos demais quanto a maior dificuldade encontrada pelos professores da amostra para alfabetizar. Os sujeitos localizaram, em maior dimensão, na instituição escolar e em suas salas numerosas um fator que dificultaria o processo de alfabetização. Como esclarece PENIN (1980), atribuindo o baixo aproveitamento escolar a causas externas à sua competência, os professores passam a acreditar que qualquer alteração no rendimento do aluno não depende deles e assim tornam-se menos insatisfeitos.
Os resultados obtidos por esta pesquisa parecem confirmar em parte os encontrados por BARDELLI (1986), em que os professores responsabilizam a organização escolar e os pais pelo mau desempenho escolar. Já, no trabalho de MALUF e BARDELLI (1991), o sistema educacional não foi mencionado pelos professores.

Nota-se que as representações dos professores sobre as dificuldades e facilidades por eles encontrados durante o processo de alfabetização são um tanto divergentes (dados da Tabela 2 e 3). Quando falavam em dificuldades para o processo de alfabetização os professores não citaram a si próprios significativamente, já ao falarem de elementos facilitadores, apontaram em grande parte para os alunos. Ao identificar nos próprios alunos a maior parte dos fatores contribuintes para o processo de alfabetização, o professor está, de forma implícita, atribuindo ao aluno a responsabilidade pelas dificuldades encontradas por ele, professor, para conduzir o processo de alfabetização.

Este dado corrobora a afirmação de ALMEIDA \& cols. (1995), de que há uma tendência em voga nas instituições brasileiras atuais, incluindo a escola, em enfatizar a análise do fracasso escolar nos aspectos extra escolares, como o aluno e sua família. Nos trabalhos de NEVES \& ALMEIDA (1996), GAMA \& JESUS (1994), MALUF \& BARDELLI (1991), MARIZ (1984) esta visão do professor está igualmente presente.

Sobre a compreensão que a criança possui do processo de alfabetização ao freqüentar a escola, a maior parte das professoras acredita que elas compreendem, pois segundo essas professoras, as crianças demonstram isso através da aprendizagem trazida pelas mesmas ao chegarem na escola e da relação que fazem entre a fala e a escrita. Entretanto, esta opinião parece um tanto dividida, pois uma parcela considerável de professores não têm certeza disso. O que denuncia uma espécie de pensamento em processo de mudança, como 
se os pesquisadores tivessem feito uma pergunta que necessitasse de maior reflexão, por talvez nunca ter lhes ocorrido.

Através dos relatos, mais uma vez, observa-se uma tendência dos professores a esperarem encontrar em sala de aula alunos com preparação prévia diferenciada, alunos diferentes da realidade que os cerca. A busca de se trabalhar com o aluno ideal ao invés do aluno real parece ainda permear o discurso, muitas vezes implícito dos professores. Uma das conseqüências possíveis desse tipo de idéia pode ser uma posição de não aceitação do aluno real, ocasionando a inadequada rotulação de alguns alunos onde uma classe "que não vão aprender nunca", obscurecendo a percepção do professor para os progressos, mesmo que pequenos, de cada aluno.

As diferentes expectativas do professor podem ser transmitidas aos alunos, que por sua vez podem se conformar com essas expectativas, seja de atribuição de sucesso ou de fracasso, segundo BAR-TAL \& GUTTMANN (1981). Os autores descreveram no resultado de sua pesquisa, o professor como a maior causa de influência para o sucesso.

Como considerações finais, as Autoras acreditam que a presente pesquisa por suas limitações remete à algumas questões: até que ponto as professoras utilizam suas crenças sobre a função da alfabetização em seu programa de aula; o que pensam esses alunos realmente ? Até que ponto existe uma coincidência na concepção entre os alunos e os professores sobre eles próprios, sobre o que lhes deve ser atribuído em suas funções e sobre o que é a alfabetização? Questões a serem investigadas posteriormente, porcerto,emoutro estudo mais amplo.

\section{REFERÊNCIAS}

ALMEIDA, S.F.C. de; RABELO, L. de M.; CABRAL, V. S.; MOURA, E. R. de O.; BARRETO, M de S. F. \& BARBOSA, $H$. (1995). Concepções e Práticas de Psicólo- gos Escolares Acerca das Dificuldades de Aprendizagem. Psicologia: Teoria e Pesquisa. Brasília: Maio - Ago., vo1.11, no 2, pp.117-134.

BARDELLI, C.,(1986). Crenças causais de professores de 1" a 4" série sobre o "mau desempenho escolar" do aluno. Dissertação de mestrado. PUC-SP, São Paulo.

BARDIN, L ,(1979). Análise de Conteúdo. Lisboa, Persona - Ed. Porto.

BAR-TAL, D. \& GUTTMANN,J.,(1981). A Comparison of Teachers', Pupils' and Parents' Attibutions Regarding Pupils' Academic Achievements. The British Journal of Educational Psychology: 51, pp.301-311.

BRANDÃO, Z.; BAETA, A. M. B. \& ROCHA, A. B. C., (1983).OEstado da Arte da PesQuisa sobre Evasão e Repetência no Ensino de 1은 grau no Brasil (1971-1981). Revista Brasileira de Estudos Pedagógicos. Brasília: 64 (147), 38-69.

COLELLO, SILVIA M.G., (1995). Alfabetização em questão. Rio de Janeiro, Paz e Terra.

COOK-GUMPERZ, J., (1991). Introdução: A construção social da alfabetização. In: COOK-GUMPERZ, J.,.A construção social da Alfabetização. Porto Alegre, Artes Médicas.

DIAZ, M. C. (org.) (1992). Psicología Social. Métodos $Y$ Técnicas de Investigación. Madrid, Eldema.

FERREIRO, E., (1988). Reflexões sobre a Alfabetização. São Paulo: Cortez: Editora.

FREIRE, P.\& MACEDO, D.,(1990). Alfabetização, Leitura do Mundo, Leitura da Palavra. Rio de Janeiro: Ed. Paz e Terra.

GAMA, E. M. P. \& JESUS, D. M. de,(1994). Atribuições e Expectativas do Professor: Representações Sociais na Manutenção da Seletividade Social na Escola. Psicologia: Teoria ePesquisa:Brasília, Set-Dez., vol.10, no 3: p. 393-410. 
KERLINGER, F.N., (1975). Investigación del Comportamiento, México, Interamericana.

LEITE, S. A. da S., (1983). Alfabetização Escolar: Repensando uma Prática. Temas de Psicologia, São Paulo : Sociedade Brasileira de Psicologia : no 3 : 85 - 95.

MACÍAS, R. F., (1990). Definitions of Literacy. In: VENEZKY, R.L; WAGNER, D.L. \& CILIBERTI, B. S.. Toward Defining Literacy. Newark. U.S.A. : IRA: International Reading Association, p.17-22.

MALUF, M.R. \& BARDELLI, C., (1991). As Causas do Fracasso Escolar na Perspectiva de Professoras e Alunos de uma Escola de Primeiro Grau. Psicologia: Teoria e Pesquisa. Brasília, vol.7, no3, Set- Dez : 263271.

MARIZ, C. L, (1985). A Criança Carente Vista por suas Professoras. Cadernos de Psicologia. São Paulo : (53), p. 69-70.

MIKULECKY, L., (1990). Literacy for What Purpose? In : VENEZKY, R.L. ; WAGNER, D.L.; \& CILIBERTI, B. S.. Toward Defining Literacy. Newark. U.S.A.: IRA: International Reading Association, p.24-34.
MORO, M. LÚCIA F., (1992). A construção da escrita pela criança e ...A construção do alfabetizador. Anais - Seminário Multidisciplinar de Alfabetização, 2, PUCSP, São Paulo , p.39-39.

NEVES, M. M. B. da J. \& ALMEIDA, S. F. C. de, (1996). O Fracasso Escolar na 5a Série, na Perspectiva de Alunos Repetentes, seus Pais e Professores. Psicologia: Teoria e Pesquisa. Brasília : Maio- Ago., vol. 12, ㄲo 2, p. 147-156.

PENIN, S. T. de S., (1980). A satisfação/insatisfação no trabalho e suas relações com as determinações objetivas da prática pedagógica desenvolvida pelo professor de $1^{\text {a }}$ a $4^{\text {a }}$ série da Rede Municipal de Ensino de São Paulo. Dissertação de Mestrado. PUC-SP, São Paulo.

ROSENTHAL, R., (1973). The Pygmalion Effect Lives. Psychology Today. Set., p. 56-63.

VENEZKY, R.L. (1990). Definitions of Literacy. In: VENEZKY, R.L.; WAGNER, D.L; \& CILIBERTI, B.S.. Toward Defining Literacy. Newark. U.S.A.: IRA: International Reading Association, p.2-16. 